\title{
Flexible 3D Printed Molds for Educational Use. Digital Fabrication of 3D Typography
}

https://doi.org/10.3991/ijoe.v15i13.11155

\author{
Alejandro Bonnet de León, Jose Luis Saorin, Jorge de la Torre-Cantero, \\ Cecile Meier $\left.{ }^{(}\right)$, Maria Cabrera-Pardo \\ University of La Laguna, Tenerife, Spain \\ cemeier@ull.edu.es
}

\begin{abstract}
One of the drawbacks of using 3D printers in educational environments is that the creation time of each piece is high and therefore it is difficult to manufacture at least one piece for each student. This aspect is important so that each student can feel part of the manufacturing process. To achieve this, 3D printers can be used, not to make pieces, but to make the molds that students use to create replicas. On the other hand, for a mold to be used to make several pieces, it is convenient to make it with flexible material. However, most used material for 3D printers (PLA) is very rigid. To solve this problem, this article designs a methodology that allows the use of low-cost 3D printers (most common in school environments) with flexible material so that each mold can be used to manufacture parts for several students. To print flexible material with low-cost printers, it is necessary to adapt the machine and the print parameters to work properly. This article analyzes the changes to be made with a low cost $3 \mathrm{D}$ printer and validates the use of molds in school environments. A pilot test has been carried out with 8 students of the subject of Typography, in the School of Art and Superior of Design of Tenerife. During the activity, the students carried out the process of designing a typography and creating digital molds for 3D printing with flexible material. The designs were made using free 3D modeling programs and low-cost technologies.
\end{abstract}

Keywords-3D printers, Filaflex, flexible mold, typography, education

\section{$1 \quad$ Introduction}

3D printing is being used in many school environments, however printing times are slow, making it difficult to manufacture parts for each student in a class, and therefore can generate frustration [1]. A previous research has shown that in a traditional classroom it is possible for each participant to produce their three-dimensional portrait with digital cutting manufacturing techniques in three hours. However, it would take six hours to print each of the pieces in 3D [2]. In addition, it is important that each student is able to participate in the manufacturing process $[3,4]$ and take home at least one piece made in the classroom. To involve students, digital manufacturing technologies such as cutting machines or printers can be used to make molds of the parts, 
which allows several replicas of the same model to be obtained. There is a long history of using low-cost 3D printers in educational environments to make parts [5, 6], but it is rare to find literature on the use of $3 \mathrm{D}$ printers in education to print molds. In order for a mold to be used to make multiple parts, it is best to be made of flexible material. However, the filament used by most 3D printers in education is rigid. This article describes the process that allows to print using flexible material in low-cost 3D printers, and thus make flexible molds that can make several reproductions.

In the industry today, digital modeling and manufacturing technologies (digital modeling and creation programs, milling machines, laser cutting, 3D printers, etc.) are widely used in the manufacture of models and molds $[7,8,9]$. Computerized processes save time, improve detail and accuracy, although they require machinery that can be more expensive. One of the digital manufacturing technologies that has been booming in recent years is $3 \mathrm{D}$ printing $[10,11]$. There are many types of $3 \mathrm{D}$ printers, from industrial printers to low-cost printers designed for individual and educational use. Low-cost printers are designed to print on rigid material such as ABS (acrylonitrile butadiene styrene) or PLA (lactic polyacid). There is the possibility of printing on flexible materials, but to ensure proper operation with this material must make adjustments in the machine (speed, temperature, height of layers, etc.).

Several types of flexible filaments can be found [12], but in this work we are going to use one of them called filaflex. Filaflex is a thermoplastic elastomer (TPE) based on polyurethane and certain additives to make it printable in a $3 \mathrm{D}$ printer. Usually $3 \mathrm{D}$ printers work with rigid materials such as PLA. There are several studies on moulds created using low-cost $3 \mathrm{D}$ printers for the manufacture of plastic injection parts $[10$, $11,13,14]$, they conclude that $3 \mathrm{D}$ printed molds, using rigid materials, are a good tool for creating prototypes of the parts to be studied or tested in a fast, efficient and economically more viable way, being able to adapt the digital 3D design later to make definitive molds. In previous studies the flexible filament has been used, as for example Filaflex, to print unions of the phalanges of the fingers of a prosthetic hand [15], it is used to create orthopedic insoles $[16,17]$. To create textile products $[18,19,20]$ or for practice mannequins [21]. It has also recently been used to create flexible molds in the design of custom prostheses for neurosurgery [22] and for the reconstruction of an ancient anatomical model [23].

In school environments, molds are usually made in the fields of artistic education, design, restoration, sculpture, engineering, architecture, etc. at both, pre-university and higher levels $[24,25,26,27,28]$. The use of traditional materials implies the use of specific classrooms prepared for working with clay, plaster, resin or silicone. The introduction of digital manufacturing technologies such as 3D printing in this educational process allows the creation of molds in classrooms that do not necessarily require specific spaces to work with these materials, and can also save time and expenses. It is important to bear in mind that in school environments, especially preuniversity, available 3D printers are usually low cost. In order to be able to create flexible molds, i.e. print with flexible Filaflex type material, it is necessary to adapt the machine and the printing parameters.

Although it is necessary to have a 3D printer and adapt it, in this work it has been decided to incorporate digital manufacturing in the classroom to make the molds and 
to promote digital competence [29, 30, 31]. In addition, making molds using traditional tools, such as modelling a piece in clay, making a silicone mold and reproducing letters using resin would take more time due to manual work and drying of materials, would be more expensive in terms of material expenditure and specific classrooms as well as additional disposable resources are needed to create formwork, gloves, containers or mixing tools [32, 33, 32].

In this article, on the one hand, we have analyzed the changes to be made with a low-cost printer (Legio3D) to be able to print with flexible materials and on the other hand, a pilot test has been carried out with 8 students of Typography, in the Higher Education of Graphic Design of the School of Art and Higher Education of Design of Tenerife to validate the use of 3D printed molds in educational environments. This subject has a part dedicated to experimental typography, where it makes sense to incorporate three-dimensional creation and work with molds. In the process, the students selected the local expression "Chos" as the starting point for creating 3D typographies using flexible $3 \mathrm{D}$ printed molds.

\section{Materials and Methods}

\subsection{Adaptation of a low-cost printer for the creation of moulds with Filaflex}

Low-cost FDM (Fused Deposition Modeling) printers often operate in a similar manner. Generally, gears and wheels push the filament yarn towards the extruder (hotend), which ends in a calibrated tip that melts the plastic and deposits it layer by layer to create the final part [34]. This operation is suitable for all types of filaments, except flexible filaments [18], because when a flexible thread is pushed, it bends and often obstructs the machine.

To avoid this, the extrusion part must be replaced. It is also necessary to adjust the filament pressure thread and increase the distance between the extruder and the extrusion platform. It is also required to take into account print speed and fill speed parameters among others [35]. The study carried out to enable the creation of flexible molds printed on Filaflex by means of a low-cost printer is detailed below. This printer is the Legio3D $(549,00 €)$ of the spanish brand Leon3D.

In this case, in order to be able to print with flexible filaments, an update of the extrusion part has been downloaded from the manufacturer's page, which avoids the blockages of this type of filaments. The digital file of this part can be downloaded in STL format from Leon3D's own page in the updates section (https://www.leon3d.es/actualizaciones-legio/).

This adaptation will have to be printed in 3D with PLA and will replace the part that is distributed with the factory printer. The design of this part presents a channel for the tightest filament that allows the material to be guided in a more efficient way, preventing the flexible filaments from overflowing from the extruder (fig 1). 


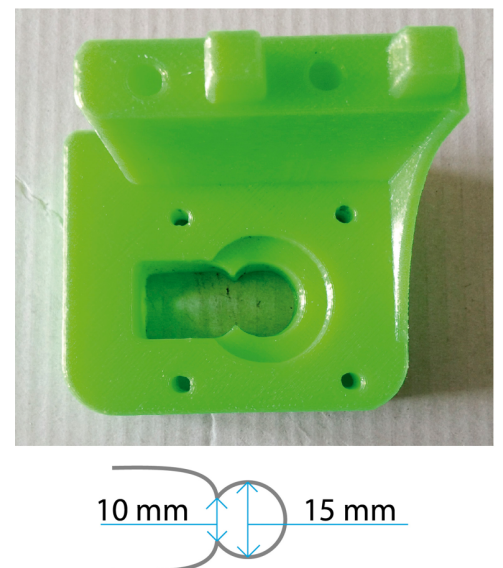

a)

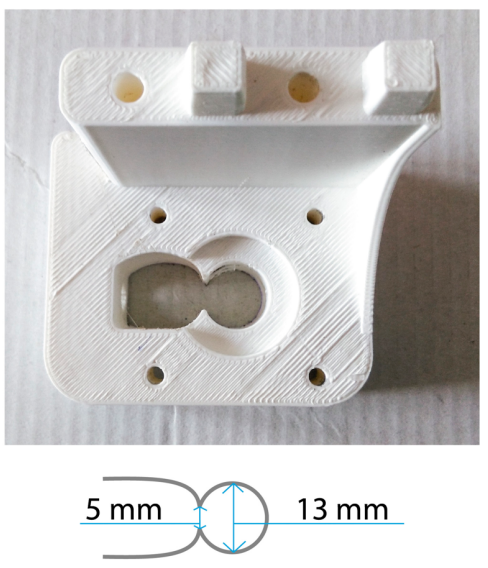

b)

Fig. 1. a) Original part that comes from the factory with the printer to print PLA b) Parts printed with white PLA for adapting flexible filament printing

Another adaptation to take into account for printing with flexible filaments is the pressure exerted on the filament. To avoid clogging, it is necessary to leave the pressure thread completely free and insert the filament manually until it begins to extrude. After this, it is convenient to adjust the thread until you notice a minimum pressure on the filament. Although for rigid filaments, it is advisable to tighten firmly, flexible filaments require less pressure.

It is advisable to adjust the height of the extruder with respect to the printing platform, because while printing with materials such as PLA requires a closer proximity, in the case of flexible filaments need more space between the extrusion nozzle and the printing platform. This distance should therefore be calibrated using the printer's own adjustment tools. Approximately 3 sheets of $80 \mathrm{gr}$. can be used as thickness between the extrusion platform and the extruder. Compared to leaving a distance of one sheet when it comes to printing on rigid materials such as PLA.

The free software used to make the three-dimensional prints was Ultimaker Cura. This program has a multitude of printing profiles according to the desired quality and the type of material used. These profiles also can be edited using different parameters to adjust the print to the specific needs of the material and the model to be printed. Different tests have been carried out in order to achieve homogeneous impressions, taking into account the main function of these impressions, which is to be used as flexible moulds. For this reason, the prints were made to a good quality, assigning a layer height value of $0.1 \mathrm{~mm}$.

From these tests, different parameters were varied and adjusted to achieve optimum print quality in the shortest possible time. It should be noted that, in general, the print speed and the speed at which the filling with the flexible filament is constructed must be lower than that used with PLA filaments, increasing the printing time, as shown in the table below: 
Table 1. Comparison of printing parameters between PLA material and Filaflex using Ultimaker Cura

\begin{tabular}{|l|c|c|}
\hline \multicolumn{1}{|c|}{ Parameters } & PLA filament & Flexible filament \\
\hline Size of the object to be printed & $55 \times 45 \times 15 \mathrm{~cm}$ & $55 \times 45 \times 15 \mathrm{~cm}$ \\
\hline Print speed & $60 \mathrm{~mm} / \mathrm{s}$ & $25 \mathrm{~mm} / \mathrm{s}$ \\
\hline Infill speed & $60 \mathrm{~mm} / \mathrm{s}$ & $25 \mathrm{~mm} / \mathrm{s}$ \\
\hline Travel speed & $120 \mathrm{~mm} / \mathrm{s}$ & $130 \mathrm{~mm} / \mathrm{s}$ \\
\hline Printing time & $2 \mathrm{~h} 14 \mathrm{~min}$ & $4 \mathrm{~h} 17 \mathrm{~min}$ \\
\hline Worn filament weight & $14 \mathrm{gr}$ & $20 \mathrm{gr}$ \\
\hline Price of the filament & $0,28 €$ & $0,80 €$ \\
\hline
\end{tabular}

In addition to varying print parameters, flexible filaments require not less than $20 \%$ infill for small parts and around 30\% infill for larger parts, compared to $10 \%$ commonly used for PLA printed parts. Furthermore, as the size of the printed molds increases, the thickness of the top layers must be increased to obtain a homogeneous surface without holes. In figure 2 you can see the appearance of holes by increasing the size of the piece and its solution by increasing the infill from $20 \%$ to $30 \%$ and the top layer from $0.8 \mathrm{~mm}$ to $1 \mathrm{~mm}$.

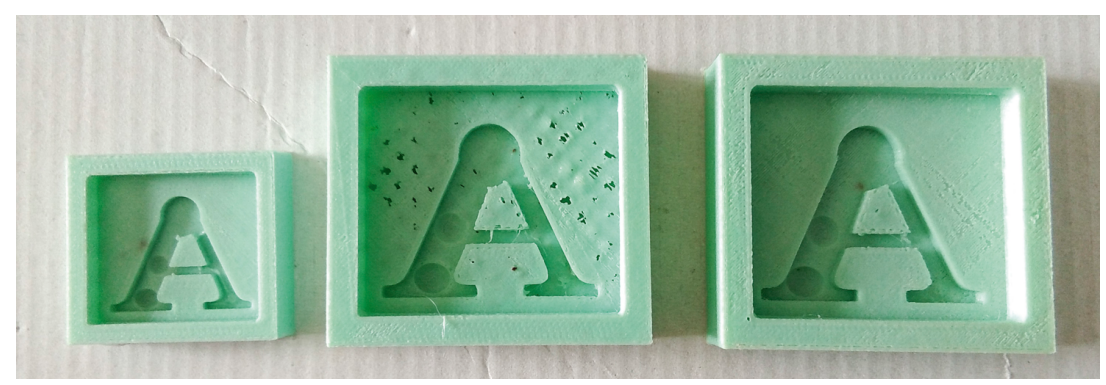

Fig. 2. Appearance of holes when increasing the size of the piece and its solution by increasing the filling from $20 \%$ to $30 \%$ and the top layer from 0.8 to $1 \mathrm{~mm}$.

The creation of flexible molds with the indicated specifications are suitable for robust pieces, however the creation of molds for more fragile or narrow pieces such as fine typographies need a greater flexibility of the mold. The printing parameters and the design of the moulds have been adapted to facilitate the demoulding of more fragile pieces, reducing the relative rigidity of the mold as well as reducing printing times. For this purpose, the density of the internal filling of the mold was reduced, using the five-step infill option. It means that the filling of the mould is carried out with a minimum infill in most of the piece, dividing the upper part in five different steps, each one more dense, making the layers with more filling until reaching the chosen filling density in the programme settings $(30 \%)$ as it reaches the highest point, where it finally closes the piece with layers higher than $100 \%$ of a millimetre thick in total (fig $3 a$ ).

This modification in the parameters of the print fill that creates a progressive fill, existing in the Ultimaker Cura program, allows a print with more empty space inside the mold favoring its flexibility. In addition, it reduces printing times and saves material. On the other hand, the shape of the mould was modified, cutting the excess walls 
to the minimum possible (fig. 3b). This step was carried out in the free program Meshmixer with plane cutting tools and subtraction Boolean operations, cutting the silhouette around the letter, leaving the walls of 3-10 millimeters approximately, improving the flexibility of the mold.

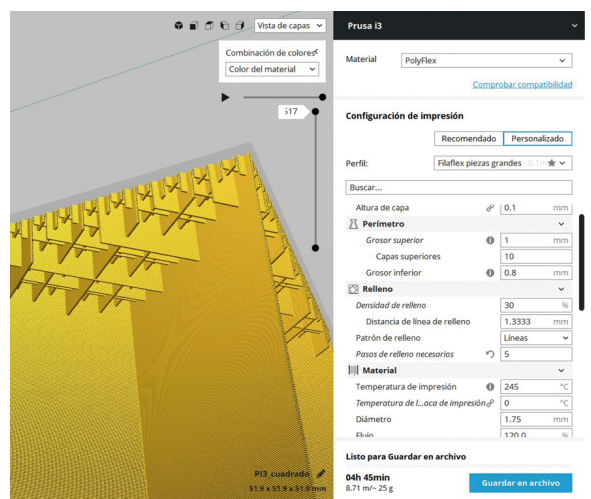

a)

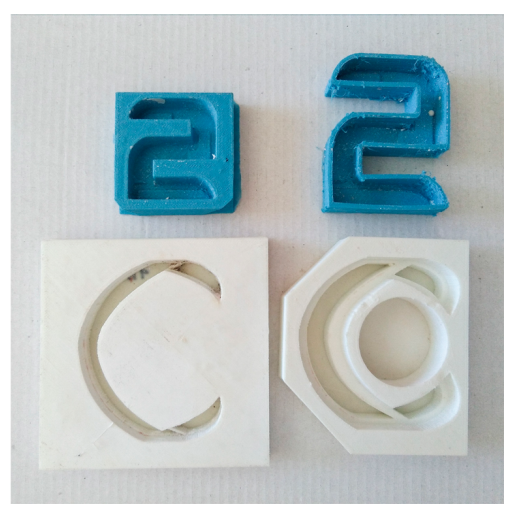

b)

Fig. 3. a) Cura Ultimaker program cutout: Density of the mold interior fill, using the five-step fill option. b) Square and modified mold with the trimming of the walls around the silhouette to 3-10 millimeters.

\subsection{Case study: Flexible molds to create 3D fonts in the classroom}

A pilot test has been carried out on a typography subject in order to introduce flexible molds in educational environments, obtain a first assessment by the participants and check the viability of the activity in the classroom. The pilot test was carried out with 8 students in the subject of Typography and Communication, which is taught in the Higher Artistic Teaching of Design, offered at the Fernando Estévez School of Art. Once the changes to be made to the 3D printer have been determined and the printing parameters have been adjusted, the aim is to validate the use of the molds in educational environments. It is also intended that, by using molds, all participants can be part of the manufacturing process and take the four letters of the word "Chos" at the end of the activity. It took two days of class, a total of four hours to make all the reproductions, once the molds were printed. The time needed to print the entire word in 3D would be approximately 190 minutes, a total of 25 hours and 20 minutes if you want to print the full word for each of the 8 students, compared to 9 hours and 25 minutes needed to print the four molds.

\subsection{Description of the activity}

The incorporation of digital manufacturing, in this case the creation of flexible moulds, in the classroom makes sense in the subject of typography, because it has a part dedicated to experimental typography. Although it is necessary to have a $3 \mathrm{D}$ 
printer and adapt it, in this work it has been decided to incorporate the digital creation of molds in the classroom to promote digital competence and digital manufacturing. It was also feasible to carry out the activity using $3 \mathrm{D}$ printing as it saves time and costs in the execution of the molds and does not require specific classrooms.

The software and hardware used for the activity, from the design of the typography to obtaining a $3 \mathrm{D}$ reproduction, was developed in the typography course over ten sessions of two hours each. The participants begin with the design of the typography in sketch mode with paper and pencil. Then the entire alphabet is created following a homogeneous design. At the end it is transferred to millimetric paper to obtain a more exact drawing. This drawing is then digitized with an Illustrator-type vector drawing program. The professional font editor FontLab (fig. 4a) is used to convert the letters into a usable font. Finally, we work with the online application Lithophane, a web application that transforms a black and white photo into a three-dimensional mold in the format ".STL" printable by any 3D printer (fig. 4b). This allows us to transform one of the designed letters into a mold without the need for 3D modelling knowledge. But the letter must be inverted horizontally in order to make the mold. Finally, the free program Meshmixer was used to trim the edges and make the mould more flexible as well as saving time and printing material.

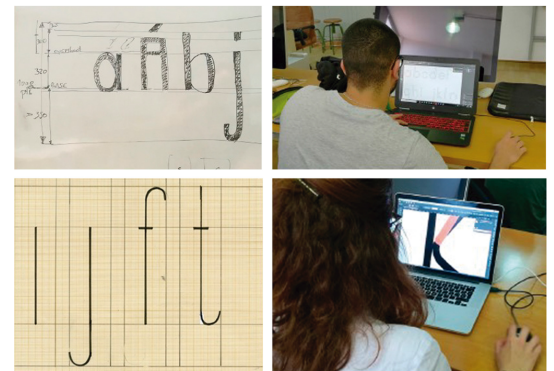

a)

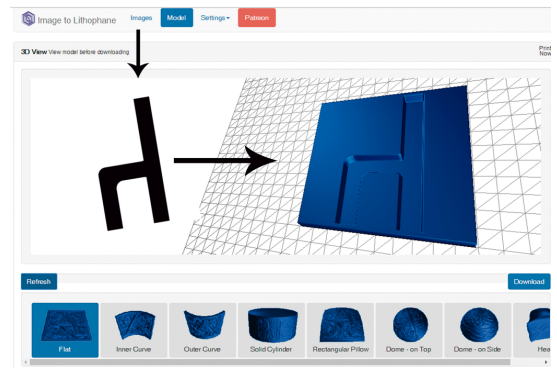

b)

Fig. 4. a) Hand sketching process, transfer to millimetre paper, digitisation with the vector drawing program Illustrator and font creation with FontLab. b) Transforming a black and white sketch into a 3D mould using the online program Litophane.

For the 3D printing of the model, the free Ultimaker Cura program is used, in which the printing parameters are entered. The low-cost printer "Legio3D" and flexible filament of the Filaflex brand are used to manufacture the molds. In this case, the molds were printed with the specific characteristics for molds, according to the research carried out in the first phase.

Finally, the molds were used to create 3D pieces of the typefaces designed with the Acrylic resin Jesmonite AC300-AC100 (fig. 5). It is an acrylic composite material supplied in two parts, a powder and a liquid. Due to its solvent-free formulation, it can be cast without damaging the moulds and without volume restriction. It is dimensionally stable thanks to its low exothermic reaction and presents a very reduced expansion $(1 \mathrm{~mm} /$ meter linear). This resin is non-toxic and easy to clean. The drying time of 
the resin, once mixed both parts is about twenty minutes so it was possible to make eight copies of each letter in two educational sessions of two hours each.
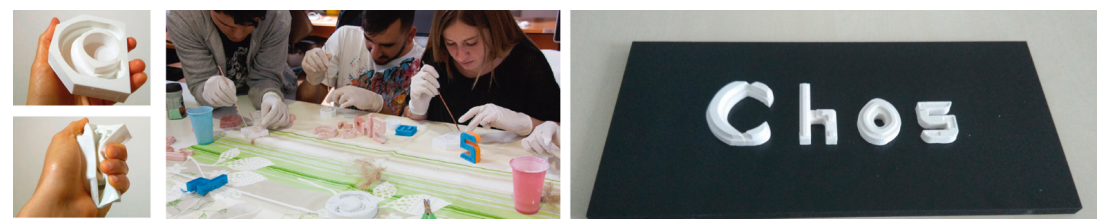

Fig. 5. Work process and result with acrylic resin to create 3D replicas of the designed fonts.

\section{Results}

Regarding the pieces created in the 3D typography workshop, we can see that each student has been able to generate in two sessions the four letters that made up the word "Chos". In total, 32 pieces have been produced. If these pieces had been printed in $3 \mathrm{D}$, a total of 25 hours and 20 minutes would have been needed to carry out the activity and the students would not be able to participate in the manufacture process. However, it took 9 hours and 25 minutes to print the four molds using Filaflex plus four hours of class to create the copies using the resin.

The changes made to the low-cost 3D printer to enable printing with flexible filament (Filaflex) were as follows:

- Print in 3D with PLA filament the piece of special extrusion for the printer legio3D of the brand Leon3D that allows to work with flexible filament. This part is available at https://www.leon-3d.es/actualizaciones-legio/.

- Adjust the pressure thread. To begin with, the pressure thread must be left completely free and the filament must be inserted manually until it begins to extrude, then the thread is adjusted until a minimum pressure is felt on the filament.

- Adjust the height of the extruder in relation to the printing platform. A distance of approximately 3 sheets of $80 \mathrm{gr}$. should be left as thickness between the printing platform and the extruder.

For the correct printing of the molds, in order to obtain a homogeneous surface without holes, flexible enough to demould the pieces easily and which adjusts the material consumption and the investment time, the following parameters must be taken into account:

- Perimeter: Upper thickness: $1 \mathrm{~mm}$. Lower thickness $0.8 \mathrm{~mm}$

- Infill: Filler density: $30 \%$ Required filling steps: 5

- Printing temperature: $245^{\circ} \mathrm{C}$ (as recommended by the manufacturer)

- Printing speed: $25 \mathrm{~mm} / \mathrm{s}$

- Infill speed: $25 \mathrm{~mm} / \mathrm{s}$

- Travel speed: $130 \mathrm{~mm} / \mathrm{s}$

- Mold shape: Cut out the silhouette around the letter, leaving the walls of 3-10 millimetres. 
From the satisfaction questionnaire that has been given to the students, the results shown in the following table have been obtained.

Table 2. Results of the satisfaction questionnaire

\begin{tabular}{|c|l|c|}
\hline & \multicolumn{1}{|c|}{ Question } & Mean about 5 \\
\hline 1 & Digital manufacturing is useful for 3D typography & 4,6 \\
\hline 2 & Flexible moulds are a good tool for experimental typeface design & 3,8 \\
\hline 3 & $\begin{array}{l}\text { It is easy to switch from 2D model in Illustrator to 3D using the online program Litho- } \\
\text { phane }\end{array}$ & 4 \\
\hline 4 & Before this activity I did not know these technologies & 2,8 \\
\hline 5 & I think it is an interesting activity within the subject of typography & 4 \\
\hline 6 & I found the workshop amusing & 4,4 \\
\hline 7 & $\begin{array}{l}\text { I was already familiar with filaflex (flexible material) for digital printing of moulds or } \\
\text { flexible parts }\end{array}$ & 3 \\
\hline 8 & My level of satisfaction with the activity is high & 4,6 \\
\hline
\end{tabular}

\section{Conclusion}

As conclusions of the first phase of adaptation of low-cost 3D printers for the use of flexible material Filaflex we can highlight that:

It is possible to design and print flexible molds using low-cost $3 \mathrm{D}$ printers, which are common in school environments. Many of the manufacturers themselves provide users with the parts (in STL format) needed to adapt the machine to print flexible filaments. Therefore, with the results of our work, it is possible to consider the implementation of printed molds in flexible material in the educational field.

By changing the infill speed and printing speed parameters, parts can be printed correctly and without holes using filaflex. By changing the filling parameters to a five-step progressive fill and minimizing mold walls to 3 - 10 millimeters, it improved flexibility and ease of demoulding, being suitable for delicate parts such as typographies, as well as reducing printing time and material expense.

Although the 3D printing of flexible material such as Filaflex is more complex than the usual material such as PLA, this research work details the adjustments needed to use this material in low-cost printers. The values described in this work are for the Legio3D printer, however, these settings should be compatible with most printers available in educational environments.

As conclusions of the second phase of the educational implementation of flexible molds for the creation of typographic pieces we can highlight that:

Regarding the activity developed in the subject, we can conclude that the introduction of flexible molds in the classroom is feasible. The students followed the usual process of designing fonts in the classroom, but they were also able to transfer some letters to a 3D mould using a simple and free program such as Litophane. Each student was able to work with the molds and obtain several pieces, participating actively in the manufacturing process. In this case it was successful to create flexible molds and not directly the printed letters and thus obtain several pieces of the same model in less time, without the need for specific classrooms and additional tools as well as saving costs. 
On the other hand, carrying out the activity using traditional materials means greater expenditure on disposable and fungible material such as silicone, formwork, glasses and mixing tools, as well as requiring a specific classroom. More time is also needed to carry out the activity as it is more laborious to prepare the three-dimensional pieces, create the mould and have the mould drying time (24-48 hours). Moreover, once the process is finished, if you want to make changes it is necessary to start with all the work from the beginning, when in a digital mold it is easy to make changes.

Regarding the satisfaction questionnaire, all the participants managed to carry out the activity correctly with the proposed means, materials and times. The students saw usefulness in the use of new technologies (4.6/5) and found it simple (4/5). They also found the workshop interesting and enjoyable (4 and $4.4 / 5)$ and found that the molds were a good tool for experimental typography $(3.8 / 5)$. With a high degree of satisfaction at the end (4.6/5). Prior to the activity, many of the participants were not very familiar with these digital manufacturing technologies, some had heard of Filaflex but had not used it (2,8 and 3 respectively out of 5).

By introducing the new digital manufacturing technologies into the classroom using flexible moulds, the student perceives more possibilities in the world of experimental typography. In addition, it should be noted that many of the students, although they were aware of the existence of low-cost technologies, had not considered the possibility of implementing them in the study of experimental typography.

\section{$5 \quad$ References}

[1] S. Nemorin, «The frustrations of digital fabrication: an auto/ethnographic exploration of '3D Making'in school, » International Journal of Technology and Design Education, vol. 27, $\mathrm{n}^{\mathrm{o}} 4$, pp. 517-535, 2017. https://doi.org/10.1007/s10798-016-9366-Z

[2] J. L. Saorin, A. Bonnet de León, C. Meier y J. de la Torre-Cantero, «Retrato tridimensional mediante la utilización de tecnologías de fabricación digital de bajo coste en entornos educativos,» Arte, Individuo y Sociedad, pp. 295-309, 2018. https://doi.org/10.5209/aris. $\underline{56796}$

[3] P. Himmele y W. Himmele, Total participation techniques: Making every student an active learner, Virginia: ASCD, 2017.

[4] A. Bonnet de León, J. L. Saorin, J. de la Torre-Cantero, C. Meier y E. García Marrero, «The Classroom as a Makerspace: Use of Tablets and Cutting Plotter to Create Pop-Up Cards in Educational Environments,» International Journal of Emerging Technologies in Learning (iJET), vol. 14, $\mathrm{n}^{\mathrm{o}}$ 10, pp. 116-131, 2019. https://doi.org/10.3991/ijet.v14i10. 10284

[5] I. M. Santos, N. Ali y S. Areepattamannil, Interdisciplinary and International Perspectives on 3D Printing in Education. IGI Global., USA: IGI Global, 2018.

[6] G. Paludo Licks y A. Canabarro Teixeira, «Smart Makerspace. A Web Platform Implementation,» International Journal of Emerging Technologies in Learning (iJET), vol. 13, $\mathrm{n}^{\circ}$ 2, pp. 140-156, 2018. https://doi.org/10.3991/ijet.v13i02.7904

[7] E. Hakimian y A. B. Sulong, «Analysis of warpage and shrinkage properties of injectionmolded micro gears polymer composites using numerical simulations assisted by the Taguchi method,» Materials \& Design, no 42, pp. 62-71, 2012. https://doi.org/10.1016/j. matdes.2012.04.058 
[8] P. Mitchell, Tool and Manufacturing Engineers Handbook: Volume VIII: Plastic Part Manufacturing, Michigan: SME, 1996.

[9] X. Li, «Exploration and Practice on Course Teaching in Plastic Injection Mold,» International Journal of Emerging Technologies in Learning (iJET), vol. 13, $\mathrm{n}^{\mathrm{o}}$ 6, pp. 101-111, 2018. https://doi.org/10.3991/ijet.v13i06.8497

[10] J. Noble, K. Walczak y D. Dornfeld, «Rapid Tooling Injection Molded Prototypes: A Case Study in Artificial Photosynthesis Technology,» de 6th CIRP International Conference on High Performance Cutting, HPC2014, 2014. https://doi.org/10.1016/j.procir.2014.03.035

[11] A. M. Suárez Castrillón, W. Tafur Preciado y P. R. Calderón Nieves, «Aplicación de herramientas $\mathrm{CAD} / \mathrm{CAM}$ para el diseño y fabricación de prototipos de moldes de inyección de plásticos,» Tecnura, vol. 19, no 46, pp. 115-121, 2015. https://doi.org/10.14483/udistri tal.jour.tecnura.2015.4.a09

[12] Impresora3D, «Impresoras 3D.com, » $11 \quad 1$ 2019. [En línea]. Available: https://www.impresoras3d.com/que-filamento-flexible-deberiamos-elegir/.

[13] H. Rodrigue, B. Bhandari, W. Wang y A. Sung-Hoon, «3D soft lithography: A fabrication process for thermocurable polymers,» Journal of Materials Processing Technology, vol. 217, pp. 302-309, 2015. https://doi.org/10.1016/j.jmatprotec.2014.11.005

[14] P. Chung, J. A. Heller, M. Etemadir, P. E. Ottoson, . J. A. Liu, L. Rand y S. Roy, «Prototipado rápido y económico de dispositivos médicos utilizando moldes impresos en 3D para moldeo por inyección de líquidos,» Journal of Visualized Experiments: JoVE, vol. 88, $\mathrm{n}^{\circ}$ 51745, 2014.

[15] A. Negrete, A. E. Achinelli y F. Pfanner, Electronic Hand Prótesis, Río Gallegos, 2017.

[16] M. Yarwindran, N. Azwani Sa'aban, M. Ibrahim y R. Periyasamy, «Thermoplastic elastomer infill pattern impact on mechanical properties 3D printed customized orthotic insole. ARPN Journal of Engineering and Applied Sciences, 11(10), 6519-6524.,» ARPN Journal of Engineering and Applied Sciences, vol. 11, n 10, pp. 6519-6524, 2016.

[17] E. Krassenstein, «3Dprint.com, » 211 2019. [En línea]. Available: https://3dprint.com/ 22255/3d-printed-insoles-gyrobot/.

[18] A. Lehmann, A. Ehrmann y K. Finsterbusch, «Optimization of 3d printing with flexible materials, » de International Textile Conference, Stuttgart, 2017.

[19] L. M. Arruda y H. Carvalho, «3D Printing as a Design Tool for Wearables: Case Study of a Printed Glove,» de Innovation, Engineering and Entrepreneurship, Helix, Springer, 2018, p. 1. https://doi.org/10.1007/978-3-319-91334-6 27

[20] Y. Martens y A. Ehrmann, «Composites of 3D-Printed Polymers and Textile Fabrics, » de IOP Conference Series: Materials Science and Engineering, San Francisco, 2017. https://doi.org/10.1088/1757-899x/225/1/012292

[21] M. W. H. Thielen y F. L. M. Delbressine, «Rib cage recreation: towards realistic neonatal manikin construction using MRI scanning and 3D printing, » de Shape Modeling International (SMI 2016): Fabrication and Sculpting Event (FASE), Berlin, 2016.

[22] S. Figari Bizzotto, D. Craiem y G. Corti, «Manufacturing of customized prostheses for neurosurgery based on 3D printing technology: first steps, » Revista Argentina de Bioingeniería, vol. 22, $\mathrm{n}^{\circ}$ 2, pp. 24-27, 2018.

[23] Ó. Hernández-Muñoz y A. Sánchez-Ortiz, «Hernández-Muñoz, Ó., \& Sánchez-Ortiz, A. (2019). Digitalización e impresión 3D para la reconstrucción de pérdidas volumétricas en un modelo anatómico de cera del siglo XVIII,» Conservar Patrimonio, vol. 30, pp. 59-72, 2019. https://doi.org/10.14568/cp2018003

[24] BOE, Real Decreto 1105/2014, de 26 de diciembre, por el que se establece el currículo básico de la Educación Secundaria Obligatoria y del Bachillerato., Madrid: Ministerio de Educación, Cultura y Deporte, 2015. https://doi.org/10.14201/gredos.128270 
[25] A. Turner, Extruder, Mold \& Tile: Forming Techniques, Cleveland: The american Ceramic Society, 2011.

[26] P. C. Cummins, Industrial Education, Volumen 69, Michigan: Cummins Publishing Company, 1980.

[27] V. Goodship, Practical Guide to Injection Moulding, Shawbury: iSmithers Rapra Publishing, 2004.

[28] J. C. Rich, The materials and methods of schulpture, New York: Dover Publications Inc, 1914.

[29] J. L. Saorin, C. Meier, J. de la Torre-Cantero, C. Carbonell-Carrera, D. Melián-Díaz y A. Bonnet de León, «Competencia Digital: Uso y manejo de modelos 3D tridimensionales digitales e impresos en 3D,» EDMETIC, vol. 6, $\mathrm{n}^{\circ}$ 2, pp. 27-46, 2017. https://doi.org/10.21 071/edmetic.v6i2.6187

[30] M. G. Cervera y F. M. E. Mon, «Explorando el potencial educativo de los entornos virtuales 3D,» Teoría de la Educación; Educación y Cultura en la Sociedad de la Información, pp. 14(3), 302, 2013. https://doi.org/10.4272/84-9745-045-0.ch11

[31] M. G. Cervera, J. G. Martínez y F. M. E. Mon., «Competencia digital y competencia digital docente: una panorámica sobre el estado de la cuestión,» Revista Interuniversitaria de Investigación en Tecnología Educativa, pp. 1 -10, 2015. https://doi.org/10.6018/riite20 $\underline{16 / 257631}$

[32] B. F. Barrie, Mold Making, Casting and Patina: For the Student Sculptor, Michigan: Thomson-Shore, Incorporated, 1992.

[33] T. Langland, From Clay to Bronce. A studio guide to figurative sculpture, New York: Watson-Guptill Publications, 1999.

[34] E. Canessa, C. Fonda y M. Zennaro, Low cost 3D printing for science, education and sustainable development, Trieste: ICTP-The Abdus Salam International Centre for Theoretical Physics, 2013.

[35] L. Adrian, J. M. Jurado, J. L. Cárdenas y F. R. Feito, «Advances for 3D printing: Remote control system and multi-material solutions, » de Conference: 26. International Conference in Central Europe on Computer Graphics, Visualization and Computer Vision, Czech Republic, 2017.

[36] B. Midgley, Guía completa de escultura, modelado y cerámica: técnicas y meteriales, Madrid: Tursen S.A., 1993.

\section{Authors}

Alejandro Bonnet de León is $\mathrm{PhD}$ candidate in the department of education at the University of La Laguna, Calle Radio Aficionados, s/n, 38320 Santa Cruz de Tenerife, Spain. His research interest lies in the fields of using technologies for digital fabrication in education. alebonle@hotmail.com

Jose Luis Saorin is senior professor in the area of engineering graphics at University of La Laguna and funder of the FabLab in Tenerife, Calle Radio Aficionados, s/n, 38320 Santa Cruz de Tenerife, Spain. His research is about new interactive technologies and digital fabrication. jlsaorin@ull.edu.es

Jorge de la Torre-Cantero is Assistant Professor at University of La Laguna in the area of engineering graphics and founder of the FabLab Tenerife, Calle Radio Aficionados, s/n, 38320 Santa Cruz de Tenerife, Spain. He is specialized in advanced graphic technologies and digital fabrication. jcantero@ull.edu.es 
Cecile Meier is an Assistant Professor at University of La Laguna at the department of fine arts, Calle Radio Aficionados, s/n, 38320 Santa Cruz de Tenerife, Spain. Her research is specialized in use of new technologies and digital fabrication in classroom.

Maria Cabrera-Pardo is a Master student in the department of education at the University of La Laguna, Calle Radio Aficionados, s/n, 38320 Santa Cruz de Tenerife, Spain. Her research is about the implementation of 3D printing in preuniversity levels of education. mariacabrarapardo@gmail.com

Article submitted 2019-06-29. Resubmitted 2019-08-09. Final acceptance 2019-08-09. Final version published as submitted by the authors. 